\title{
Illiteracy among caregivers: implications for children's educational and social development
}

\author{
Barrington Makunga, Catherina J. Schenck, Nicolette V. Roman and Gary Spolander.
}

\begin{abstract}
The ability of primary caregivers to provide a healthy, nurturing and stimulating environment for their children is essential for children's educational advancement and emotional development. However, caregivers who live in the rural areas in South Africa face many challenges, ranging from acute poverty and limited education and skills to feelings of social inadequacy and marginalisation. These factors directly and indirectly affect their ability to care for children and thus these children's educational progress and future economic and social prospects. This article describes the experiences of illiterate caregivers in the Eastern Cape, South Africa, in attempting (or otherwise) to assist the children in their care with their schoolwork. An exploratory study was conducted in the village of $\mathrm{Ku}$ Jonga in the Eastern Cape's rural Coffee Bay, which used focus groups comprising caregivers and teachers. Among the findings was that many children's lack of educational advancement in the school system has complex origins, but that the illiteracy of their primary caregivers (which results in their inability to help with schoolwork or to provide the motivation or environment for learning) is a leading cause. A key conclusion was that caregivers, teachers and external stakeholders (for example the government and civil organisations) need to work together to arrive at a common understanding of the specific problems and priorities of rural communities, particularly with regard to education, and to introduce practical initiatives to help these communities become more motivated, productive and self-sustaining.
\end{abstract}

\section{Introduction}

A healthy, nurturing and stimulating environment enhances a child's motivation, achievements and well-being at school (Menheere and Hooge 2010). Therefore, the ability of primary caregivers to provide such an environment for their children is paramount. However, caregivers in South Africa, especially those living in rural communities, face many challenges, including poverty, limited education and skills, and social isolation (Mathambo and Gibbs 2008). These factors directly and indirectly affect their ability to care for children, and also influence children's educational and social development.

The general literacy levels of caregivers have a marked effect on a community's health and education standards, economic activity, social integration and cohesion. Illiteracy limits caregivers' ability to understand messages (Martínez and Fernández 2010). Being illiterate, therefore, can have a negative impact on the health, hygiene and nutrition levels in 
households. Children in these households often drop out of school as illiterate caregivers tend to have lower educational expectations and work- related aspirations for both themselves and their children (Drajea and O'Sullivan 2014; Martínez and Fernández 2010). The United Nations Educational, Scientific and Cultural Organization (UNESCO 2010) found that illiterate persons are often denied social recognition. As a result, illiterate caregivers or parents often have low self-esteem which deprives them of the assertiveness needed to encourage and inspire their children to attend and excel at school.

Weigel, Martin and Bennet (2006) and Cooter (2006) refer to intergenerational illiteracy as a socio-economic cultural phenomenon whereby illiterate caregivers inadvertently create home conditions that hinder their children's reading and writing skills development. According to Cooter (2006) and Drajea and O'Sullivan (2014), intergenerational illiteracy often exists in high-poverty urban and rural settings where teachers note that caregivers have low literacy skills. Roman (2004) and Khan, Iqbal and Tasneem (2015) add that children whose caregivers did not complete school are more likely to be illiterate and are more than five times as likely as children from literate families to drop out of school. Illiteracy also imposes a significant burden on family and/ or external support systems as illiterate adults are dependent on others to function and survive. This implies that illiterate caregivers may not have the knowledge and skills to deal with the challenges they encounter in their daily interactions with their children, such as assisting them with homework and understanding and reacting to letters and other notifications from teachers.

In studying teacher-caregiver relations, Lemmer, Meier and Van Wyk (2006) found that a child's educational development is a dynamic process, and teachers and caregivers should ideally work together for the ultimate benefit of the child. Such a partnership ensures that the school and the family collaborate in closing the gaps that exist between what the school intends to achieve and what the community expects of their children's education (Lemmer, Meier, and Van Wyk 2006; Loughran 2008). However, not having the confidence and skills to forge such a partnership could hinder the collaborative process (Menheere and Hooge 2010).

Notwithstanding the clear importance of parental support for the development of their children, there is a gap in the literature on the challenges illiterate caregivers face in assisting their children with their daily schoolwork. This article describes some of the experiences of illiterate caregivers in their attempts to support their children in doing their schoolwork. The caregivers in question reside in the village of Ku Jonga in rural Coffee Bay in the Eastern Cape province of South Africa. A key motivation for the study was that arriving at a better understanding of caregivers' experiences could help social service practitioners, the government and other stakeholders to provide the necessary support.

According to Statistics South Africa (2014), the King Sabatha Dalindyebo local municipality comprises two magisterial rural communities, namely Mthatha and Mqanduli. Coffee Bay falls within the Mqanduli magisterial district. It covers an area of 3028 square kilometres and has a population of 451710 , with the number of individual households 
standing at 95382 (2011 figures). Of the total population, 57.8 per cent are regarded as illiterate, 91 per cent have no access to electricity, 93.3 per cent have no formal sanitation facilities, and 77 per cent are unemployed. Together these factors provide a far-fromconducive context for educational development. The Eastern Cape province of South Africa is known for its consistently low matriculation pass rates (Department of Basic Education 2014). Given the above-mentioned factors it is understandable why the Eastern Cape province has such a high illiteracy rate. Indeed, UNESCO (2010) affirms that illiteracy is the price we pay for a failed education system. There are four primary schools in the village of Ku Jonga that are attended by children from the rural community. This community was selected as the setting for the study owing to the high illiteracy rate among the caregivers in the community. A traditional chief heads up the community as well as a ward councillor who is politically deployed by the local municipality.

\section{Theoreticalframework}

Two interlocking theories guided this research study, namely Bronfenbrenner's ecological systems theory (1979) and Bowen's family intergenerational systems theory (1978). Bowen (1978) suggested that individuals cannot be understood in isolation from one another; rather they must be seen as part of their family. Bronfenbrenner (1979) viewed children's development in the context of the systems of relationships that shape their environment. Bronfenbrenner suggested five levels which he believed to be interrelated and which could have an impact on a person's development, namely (a) microsystem, (b) mesosystem, (c) exosystem, (d) macrosystem, and (e) chronosystem (Visser 2007). Bronfenbrenner (1979) believed that the innermost level (microsystem) is the immediate setting surrounding the developing person, such as home or school. The next level (mesosystem) is not so much a setting as the relationship between settings. However, Bronfenbrenner asserted that the interconnections could be as decisive in the way they influence human development as events taking place at the first level.

Bronfenbrenner (1979) explained the third level (exosystem) as a level or structure that involves events in settings where the developing child is not even present. An example is a place where the parent or caregiver is employed, which could have a profound effect on the child's development. According to Bronfenbrenner (1979), the fourth level involves aspects of the social environment that may connect many members of a culture or subculture. The ecological system's perspective, therefore, emphasises the potential of human beings to respond constructively to an ecologically compatible social context. The fifth and final level of Bronfenbrenner's ecological systems theory is the chronosystem. At the chronosystem level, consideration is given to all experiences that the developing persons have had during their lifetime, including environmental and historical events (Penn 2005).

\section{Bowen's theory}

According to Bowen's theory (1978), the history of the family creates a template which shapes the values and experiences of each generation and determines how such experiences are passed down from one generation to the next. 
Central to this study is the intergenerational transmission process which is concerned with how the family reinforces the beliefs of the family as they pass through the generations. Bowen's intergenerational transmission process looks specifically at how family members refer back to previous generations. Such a process strengthens relationships and attachments among family members.

From what has been imparted by Bowen, it is clear that the majority of the children in rural areas grow up influenced by multigenerational transmission processes. In other words, they find themselves subjected to family projection processes. Families continue to reinforce family beliefs, with grandparents being the main purveyors of the family values that have been passed down from one generation to the next.

\section{Method}

This study used an exploratory research design. Neuman (2006) explains that an explorative research design is mainly used with qualitative research and is the first stage in a sequence of studies focusing on the "what" questions. The intention of the study was to explore the experiences of illiterate caregivers and the support systems available to them for helping children with their schoolwork.

The population for this study was caregivers who had received the minimum of education or no formal education at all. Furthermore, snowball and availability sampling was used. Minimally educated and illiterate grandfathers, grandmothers, fathers, mothers, stepfathers, stepmothers, aunts and uncles who care for schoolgoing children were included in the study. Access to the community was provided by the chief in the area, since he was the gatekeeper of the community. The chief assisted in approaching and inviting participants who met the sampling criteria, which were that a person should have had minimal or no schooling and should be caring for schoolgoing children. An invitation from the chief could mean that people are not really able to refuse to participate. Yet many caregivers were clearly very eager to participate in the study and provided names of other caregivers who met the criteria.

Focus groups were used as the most suitable method of collecting data as they gave rise to a better understanding of how people felt or thought about issues (De Vos et al. 2002; Krueger and Casey 2014). Interviews were conducted at the "palace" of the chief which was the most convenient and only safe space available for focus groups, given that the area is underresourced. The ward councillor, who represented the government's political interests, was also consulted on how to identify participants meeting the relevant criteria. The interviews were conducted in isiXhosa and videotaped with the permission of the participants. Field notes were taken and the data were transcribed and translated from isiXhosa to English. Ethical approval for the research was given by the University of the Western Cape's Research and Ethics Committee.

Individuals from five different focus groups from $\mathrm{Ku}$ Jonga village in the Tshezi administrative area of Coffee Bay were interviewed. Two of the focus groups consisted of 
teachers from two different schools, and the other three groups consisted of illiterate caregivers from the community. Of the caregivers, group 1 consisted of five men and four women, group 2 consisted of one man and five women, and group 3 consisted of seven men. In total, 22 caregivers participated in the study. During the first focus group session, it was clear that for cultural reasons the women did not speak in front of the men, and the men spoke on behalf of the women. Permission was then obtained from the chief and the participants to have separate groups for the male and female participants. One man, however, turned up in the women's group. He was welcomed by the women on the understanding that everyone would have an equal opportunity to share their views.

\section{Research ethics}

The research ethics guiding the research included the following: Consent forms were signed by the participants after it was explained to them that their participation was voluntary and that they had the right to withdraw from the study at any time. Participants were reassured that only information related to the study would be collected and that their privacy would not be compromised. Anonymity was ensured by omitting the names of individuals on written transcripts and allocating numbers to the participants instead. The interviews were held in a quiet room at the chief's palace to ensure privacy and confidentiality.

The study followed Creswell's thematic data analysis which entails following eight steps to organise the data into a number of themes (Creswell 2007).

\section{Results}

Demographic Data of Caregiver Participants In summary, the biographical details of the caregivers are given below.

\section{Gender}

Of the 22 caregiver participants, 10 were female and 12 were male.

\section{Age}

The ages of the participants ranged from 36 to 69 years. In this range, only two were in their thirties and five in their forties, while the majority (15) were more than 50 years old.

\section{Marital Status}

Seven caregivers were married, while 15 were raising children as single parents, having never married or been divorced or widowed. This affirms the findings of Statistics South Africa (2014) that most children in South Africa are raised by single parents.

\section{Number of Children in the Household}

The 22 caregiver participants were caring for 87 children in total. Of these, 31 children were in the care of their grandmothers, 20 were in the care of their mothers and 36 were in the care of their fathers. The average number of children per household was four. Two participants reported caring for eight children each, and one male caregiver reported caring for six children. 


\section{Level of Education}

Of the 22 caregiver participants in the three different focus groups, three reported having studied as far as higher primary school level, two reported having dropped out at the foundation phase, and 17 reported that they had never attended school and could not read or write one or two sentences or read or write their names.

\section{Teachers from School A and School B}

The fourth and fifth focus groups concentrated on the available support that the teachers could offer to caregivers in their endeavours to support their children's education. Nine female and two male teachers were selected by the school principals. All teachers held a diploma or degree in education and were between the ages of 30 and 50.

Most classrooms were overcrowded with between 22 and 89 children in a class, with particularly high numbers at the lower levels. Teachers in school A seemed to be frustrated by the lack of participation of the caregivers in school activities, and the lack of support from the provincial Department of Basic Education. It was observed that the school buildings were dilapidated and windows were broken in almost all classrooms. One of the schools appeared to have been initially built by contractors, but was never fully completed.

\section{Themes}

The themes and sub-themes identified from the interviews are outlined below.

\section{Theme 1: Caregivers' Reasons for and Experiences of Being Illiterate}

According to Statistics South Africa (2014), the illiteracy rate of the people who live in the Eastern Cape is close to 60 per cent, which is in stark contrast to the estimated literacy rate of 92 per cent for South Africa as a whole. The caregivers in the study confirmed that they lacked reading and writing skills. One of the reasons given for being illiterate was that they had not been to school at all or had left school early: "I have not been at school. I am not learned at all ... my wife never went to school" and "I did a little bit of schooling, although I left at lower grades". Even more poignant were the feelings of frustration at being illiterate: "It hurts to have no knowledge on what your child is trying to write. Illiteracy is an evil thing." The latter comment by one of the caregivers set the tone for additional problems, such as low self-esteem among the caregivers and their low level of involvement in school activities (Farris and Denner 1991). The impact of illiteracy extends far beyond the person's inability to read and write; it also affects the health and well-being of the person and his/her family. Moreover, according to UNESCO (2010), illiteracy puts people at a disadvantage for life as it reduces their socio-economic opportunities and their political participation prospects and, above all, it damages their self-esteem. In short, illiteracy is a major exclusionary factor and a violation of human rights (UNESCO 2010). 


\section{Theme 2: Reasons for Children Being Cared for by Grandparents and Single Parents}

Lunga (2009) highlighted aspects such as unemployment, teenage pregnancies, school dropouts and the death of parents as the main reasons for grandparents assuming responsibility for their grandchildren.

Thirty one of the 87 children in this study were cared for by their grandparents. Grandparents mentioned aspects such as teenage pregnancies which led to these youngsters living with their grandparents. Their views were supported by the teachers: "Children drop out at very early stages ... get pregnant and after giving birth, they always leave those little ones under the care of their grannies ..."

Male participants confirmed that they were left by their wives and expressed their experiences of raising children as single parents. "Wives leave us, because there are no jobs (for the men) to feed them and their children." This was further confirmed by another father: "I grew up in this village ... my wife left me with two children, a boy and a girl. ... Their mother left them in my care."

The Sonke Gender Justice Network (2013) indicates that in South Africa 40 per cent of children live with their mothers, three per cent live with their fathers and 23 per cent live with both their biological parents or grandparents. In the study reported in this article, the high number of children (36) being cared for by their father or grandfather exceeded the norm an interesting phenomenon warranting further research.

Mathambo and Gibbs (2008) suggest that the emergence of this pattern of grandparents acting as primary caregivers to their grandchildren risks the health of the intergenerational bond with the children's biological parents. As the children grow, grandparents often assume that they will be cared for by their children, but this social relationship is now fractured as children continue to give birth and leave the children with their grandparents. This highlights the added burden of the responsibility placed on the elderly. Grandparents often find these added responsibilities increasingly stressful, particularly if they are struggling with health and finances, and even more so if they are single.

Kinyua (2013) indicates that most grandparents find themselves in a difficult emotional, social and financial situation. This is confirmed in the next theme.

\section{Theme 3: Challenges Experienced by Caregivers/Grandparents}

The challenges experienced by the caregivers are thematically discussed below.

\section{Challenge 1: Illiterate Caregivers Are not Able to help Children with Their Schoolwork}

In this study, 20 of the 22 participants had never been to school or had had very little education. The caregivers therefore lacked the knowledge and skills to assist their children in general and in particular with their schoolwork: 
I am not learned at all, so I cannot help my children with schoolwork. I often go out and look for piece-jobs ... and the eldest daughter normally prepare and help others with everything in the house ... she is doing grade 7.

This comment emphasises the dilemma of the single parent not having support in the home to assist in the caring of the children, which often results in older children taking over the role of parent. The implied risk, according to Osborne and McLanahan (2007), is that children who adopt the role of parent end up dropping out of school.

The caregivers further shared that the children did not receive any assistance with their schoolwork: "... all they [children] are by themselves. I don't know what they are being taught." "We are not learned people, our children are ... what they study is not known to us." One of the parents indicated that it is more than illiteracy that prevented them from attending to the children's schoolwork: "I must confess, most of us are not motivated enough to support our children with schoolwork." Their lack of interest in supporting the children under their care might be linked to their not valuing the children's education owing to their own educational deficiencies.

Hoover-Dempsey et al. (2001) stress the importance of parents' involvement in children's schoolwork which can include a variety of activities, ranging from the establishment of home structures that are supportive of learning to patterns of interactive behaviour intended to enhance the child's grasp of his/her homework.

What is important is not only the direct support given in the homework domain, but also the creation of a supportive or conducive environment for learning. Caregivers' level of involvement influences learner outcomes. Such influence takes place through a caregiver's modelling, reinforcement and instructions, which have the potential to translate into positive attitudes to homework and feelings of personal competence and self-regulation (Hoover-Dempsey et al. 2001; Pomerantz, Moorman and Litwack 2007). Cooter (2006) warns that low literacy levels can be passed on to the next generation.

The fact that caregivers are unable to provide practical assistance or act as true role models because they do not value education discourages their children from learning. As a result, children may simply lose interest in their studies and drop out of school early.

\section{Challenge 2: Socio-Economic Challenges/Poverty}

In addition to the struggles faced by the caregivers in supporting children with their schoolwork, caregivers invariably experience deep poverty. One of the fathers shared that he could not cope with the financial burden of raising the children on his own, to the extent that some of the children had had to be removed. "I lost my wife in 2009 and I lived with eight children. Three of the eight are with me, attending school ... and five were removed by the social workers to a place of safety (child care facility) as they were still very young. I have not been at school." 
Perret, Anseew and Mathebula (2005) define poverty as the inability to attain a minimum standard of living, measured in terms of basic consumption needs or the income required to satisfy these needs. The authors add that poverty encompasses a lack of power and the inability to afford decent healthcare and education. The findings of this study confirm the state of extreme poverty that caregivers invariably experience.

The caregivers participating in the study found it difficult to provide for their children's physical and educational needs:

Oh, my brother [addressing the researcher] ... the biggest challenge we all face is hunger ... This affects our children's education ... I am telling you, how can you learn on an empty stomach? ... We used to plough mealies, rich in stock, but all of those are history. We do not have herds of cattle as our forefathers used to have ... We are deep in poverty. For me that is the worst of all.

The dire circumstances of the community were elaborated on further:

This community is starving, there are no jobs ... Our sons are drunkards in this community; we do not get help from anybody ... I am even unable to buy them [the children] clothes, school uniform, bus fare. Nothing, you see.

The caregivers then also expressed their awareness of the effect that poverty was having on the children:

... our children are laughed at; as a result their self-esteem drops. This affects their learning.

Our children know they are from dilapidated mud-made rondavels [huts], sometimes wear torn socks. At schools, children tend to boast about their homes, and at times here at school, children are asked to take off their shoes for certain exercises. These are embarrassing to children. If you were educated you would be living a better life and your children would be benefitting from the lifestyle.

... we do not have electricity here, like in other villages. If your child wants to study until late, you have to buy paraffin or candles. Where is money for all these things? The grant is very little. I buy them food; one set of clothes is finished. Thirdly, it seems as if the government has ignored this village. I feel isolated and it is not accessible to transport. If you are sick you will die in the house. I heard people talk computers; I so wish my children could have one and teach me how to use it too.

Teachers also confirmed the impact of poverty on the children's education:

Learners come to school in dirty and clumsy uniforms; some come on empty stomachs, without pencils, books and some without uniforms ... it is understood. People in the area 
are jobless, so their sons and daughters prefer to move to other provinces for jobs, leaving their young ones with uneducated grannies.

Perret, Anseew and Mathebula (2005) and Martínez and Fernández (2010) explain that illiteracy and poverty give rise to a number of challenges, including alienation from the community, food insecurity, crowded homes, and the fragmentation of the family, and have a negative impact on health, education, economic activity and social integration.

\section{Challenge 3: Caregivers Struggle to Manage the Behavioural Problems of the Children}

Participants shared that they experienced challenges in managing the children, especially those who had dropped out of school who often displayed behavioural problems such as using drugs and alcohol:

"The eldest son dropped standard 8 and is more on drugs and alcohol. The other one also left school at lower grades and I heard he is in Mthatha'." "One son left school while he was doing standard 9. When I asked him why, he had no answers for me. He is a drunkard ..."

In light of the responsibility that caregivers have to carry on a daily basis, it is understandable that their energy levels are often depleted. The caregivers confirmed that they felt helpless when it came to providing their children with educational and emotional support. In such a situation, children might experience abandonment, social isolation and a low self-esteem (Carlini-Marlatt 2005). Caregivers are therefore in great need of support and empowerment so that they can cope with these parenting challenges.

\section{Challenge 4: Limited Access to Support and Services}

In South Africa, families in rural communities face many obstacles in trying to access proper social, educational and economic services as well as support to help their children with, among other things, their education (Mathambo and Gibbs 2008).

The participants expressed their dissatisfaction with the lack of support from both the government and other service providers:

I want to emphasise the lack of support from the government. Go to Mthatha and other parts of the province; they are given tractors to plant whatever. Children cannot be motivated if they are hungry. I cannot as well get motivated if I am hungry ... our children leave school at very early ages and in lower grades. They force themselves into teenage marriages, dropping out of school. We are not employed here ... there are no jobs ...

Electricity - we do not have all those things. Children study [with] candles and paraffin. If I do not have money to buy those ... they will study on wood fire light. Yes, it is true; we are not getting support from the government. Look at our community; there is not even one

\footnotetext{
${ }^{1}$ Mthatha is the closest city to the area.
} 
road into the community. Your car [to the researcher] ... I am sure was hit by the big stones you passed before getting in here.

Over and above the lack of services, the school environment is not conducive to children being properly educated. Villages and rural communities are difficult to reach and the physical condition of schools is inadequate. Learner performance, in comparison with schools in urban areas, is weak (Department of Basic Education 2014), and the Eastern Cape has earned the dubious reputation of consistently producing the lowest matric pass rates in South Africa (Quintal 2016).

Both caregivers and teachers attributed some of the children's learning problems to the age and dilapidated nature of the school buildings and classrooms.

Yeah, it is a bit challenging ... children in our school are not inspired by anything, or by anybody, for that matter. They come at school dirty; even the classrooms as you can see, are dilapidated ... They are not appetising at all. So I cannot put blame to illiteracy per se of anybody really. The whole class is up to no standard.

\section{Theme 4: Role Reversals: Children Have to Take on Parent Responsibilities}

Because caregivers in this study were elderly and single (in many instances, single males), children had to assume responsibility for the household and daily chores, which affected their schoolwork. The teachers shared that: "Children tell us that they wake up very early in the mornings, do house chores, such as fetching water from the rivers and helping in the manufacturing of mud-building blocks, before they are allowed to come to school." Another teacher explained:

"After school he [a pupil] had to put his books down and go out to look for the cattle ... the learner was not given enough time to look at his homework ..."

It was further shared that the children also played the role of parents. According to the teachers, cultural values played a significant role in this regard. Some caregivers believed that children should assume responsibility to lead the household when their caregivers were at either "grass-cutting" or "home-beer-drinking" gatherings. "Most homes are generally led by children, truly speaking. The grannies enjoy home beer and could go out as early as nine in the morning and return home very late."

Children of schoolgoing age need parental attention, guidance, love and care, physical and social security, and the opportunity to play with friends (Nelson Mandela Children's Fund 2001). The report by the Nelson Mandela Children's Fund (2001) concluded that a complex set of problems or a combination of factors heightens the risk of children heading up families. These responsibilities can be associated with social expectations about acceptable behaviour for each gender, sexual orientation and the child's role within the family (Brown 2008). According to Brown (2008), the history of the South African family creates a template that shapes the values, thoughts and experiences of each generation and how 
these are passed down to the next generation. The way emotional processes in the family are transferred and maintained over the generations was evident in the findings of this study. Caregivers indicated how their family beliefs should be re-enforced, as suggested in the following remark:

"Then, we had big herds of cattle with wide grazing fields, and we also ploughed mealies; there was no hunger like in these days. Our children can be helped in following our footsteps ..."

Children assumed these responsibilities because the caregivers believed it was their place in the family to do so. This finding prompts consideration of the theme below.

\section{Theme 5: Children Find Their Own Support}

According to the Scottish Executive Education Department (SEED 2005), parents are the first and ongoing educators of the children they care for and, as such, should receive information and support to help their children's learning at home. Sound relationships create opportunities for a child to discuss his/her learning with an adult, who can act as a mentor and help with the setting of goals for successive stages of the learning process (SEED 2005). Cuban (2011) adds that high performance is dependent on a child's education involving the caregiver, the teacher and the child.

By contrast, the participants in this study indicated that their children used other forms of support to do their schoolwork:

Because I am not educated, when they come from school they help each other with their schoolwork. I prepare food for them.

Another participant praised the abilities of the eldest daughter:

Yeah ... she is very clever, she is doing grade $9 \ldots$ and her siblings are still at lower grades. She is good, assist them ...

\section{Theme 6: Illiterate Caregivers Tend not to Value Education}

Cuban (2011) and Christenson and Sheridan (2001) promote the idea that parents and teachers should work closely together as partners. This should include meeting regularly to discuss the children's performance. When meetings of this nature occur, the following benefits are realised:

1. Children normally achieve high marks and get better results at the end of the year.

2. Caregivers are able to learn more about the school's processes and procedures.

3. Caregivers are able to learn new ways of supporting their children with their homework.

4. Children become more motivated because they can see that their caregivers show an interest in their studies. 
However, the participating teachers' statements indicated that caregivers were not attending meetings organised by the schools:

You know! I don't know how many parents' meetings were called only this year, but you will find two or three coming.

It is worse - caregivers do not honour parental meetings or even pay spontaneous visits at school.

According to Menheere and Hooge (2010), parental involvement includes the upbringing and education of their children, both at home and at school, with parental participation being defined as active participation of parents in school activities. Christenson and Sheridan (2001) conclude that the purpose of caregiver involvement in education is to become part of a shared learning context which in turns boosts children's learning and development potential.

The participants in the caregiver focus group confirmed that there was poor attendance at school meetings. One of the participants expressed his concerns about such nonattendance: "There are meetings called by teachers; our people in this area do not attend those meetings. In those meetings, but even them are scarce ... are not often called ... my wife and I always receive letters from teachers. Imagine if you are illiterate how you can take those letters serious." The latter comment clearly indicates the disjunction between teachers' expectations and the realities of the caregivers.

Cuban (2011) and Menheere and Hooge (2010) highlight the importance of partnerships and suggest different approaches for improving relationships between teachers and caregivers. Poor relationships or weak partnerships between the two sets of role players may discourage caregivers and make them feel worthless and unable to assist with their children's homework.

\section{Discussion and conclusion}

This study explored the experiences of illiterate caregivers of children, as well as the children's teachers, in a poor community in the Eastern Cape. A complex picture of poverty, illiteracy, low self-esteem and sometimes misplaced cultural values was painted by the caregivers and teachers. Clearly, illiterate parents felt disempowered and helpless to assist their children. This was further exacerbated by deep poverty, social/ community-based problems and little or no support services from government and other stakeholders for people in rural areas. What was also highlighted was the disjunction between the factors that might support educational achievement, on the one hand, and the actual education system and prevailing rural and cultural context, on the other.

Caregivers' recommendations focused on the need to deal with the complex and interrelated problems by focusing on the root causes in the area. Practical recommendations made by the participants were as follows: 
1. "Recognising traditional leaders so that the rural people's voices can be heard by those in authority." This was a very interesting recommendation given the current political context - that is, where the ward councillors and those who should represent the people are political appointments who lack experience and interest in looking after other people's well-being. This highlights the importance of those in need having a voice to advocate on their behalf for resources and support.

2. Residents in this particular rural part of Coffee Bay traditionally relied on agriculture. Consequently, they believed that to help eradicate poverty and unemployment, the Department of Agriculture and Rural Development should provide the community with modern means of farming, such as tractors and irrigation systems. They further recommended that the school syllabus include agriculture, tourism and other vocational subjects so as to provide children with relevant skills for the rural Eastern Cape. They realised that it was impossible for all to have jobs, but the Department could facilitate the training and development of the residents so as to use "the wealth of the Eastern Cape soil and vegetation".

3. Since it was found that many of the children were being looked after by caregivers other than their own parents who had moved away in search of work, participants recommended that the root causes of poverty in areas such as the Eastern Cape be eliminated. Good governance, job creation, proper service delivery and building of infrastructure (roads and electricity) are essential if migration to other provinces is to be prevented. The Eastern Cape is the province known for the highest out- migration to other provinces like the Western Cape and Gauteng for the purpose of searching for work (Hamann and Tuinder 2012; Harmse, Blaauw, and Schenck 2009).

The caregivers emphasised the need for two main forms of support:

1. NGOs and government departments such as the Department of Social Development need to assist with the development of self-sustaining projects, to build capacity and to empower caregivers to cope with the challenges they face in raising their children. In addition, programmes such as Adult Basic Education and Training (ABET) were viewed as having the potential to capacitate and empower marginalised caregivers.

2. The caregivers realised that they should be involved in their children's schoolwork but they required support from the teachers so that they could make their homes more learning-friendly. Likewise they emphasised that it was not always possible to visit the school owing to distance, the need to care for other children and the issue of low self-esteem (feeling ashamed). As a result, it was concluded that schools and caregivers need to negotiate more appropriate ways to work together.

Important recommendations made by the teachers were as follows:

1. Teachers recommended that the schools be upgraded and a curriculum be devised that is relevant to rural children. This is a particularly urgent need as the current curriculum and examinations disadvantage rural children who are not exposed to computers and other technological devices. Teachers also recommended that the school environment be made more dignified, for example classrooms should be constructed of proper building materials and should be fully furnished and maintained. 
2. The teachers recommended that they should engage more with caregivers and with the community to listen to their challenges. This would help in the development of intervention strategies relevant to the needs of both the children and their caregivers.

3. Provision should be made for the introduction of family strengthening and parenting programmes. It was also recommended that relevant government departments and civil organisations seriously engage with families in rural areas to help them strengthen the bonds between family members and embrace strong value systems. In particular, single fathers and elderly men, who seemed to be increasingly responsible for caring for children, needed to be provided with parenting skills.

The view that (in the eyes of one of the caregiver participants) "illiteracy is an evil thing" sums up the sense of intergenerational disempowerment and distress that is playing out in the Eastern Cape. If not redressed, the situation will only worsen, and more and more children will miss out on the opportunity to fulfil their potential and make a valuable contribution to the economy and society as a whole. Already falling behind most other African countries in terms of the quality and relevance of public education offerings, South Africa potentially faces a bleak economic future as well as the prospect of social discontent (prompted by growing unemployment and hopelessness) spiralling out of control. Clearly, there is no time to waste in tackling this dire but treatable situation.

The government and civic organisations have the opportunity to take this study's thoughtful and first-hand recommendations seriously and use them to prioritise infrastructural, educational and social development projects in affected rural areas. This will also provide an important foundation for stronger teacher-caregiver dynamics, which will stand communities in good stead for generations to come. 


\section{References}

Bowen, M. 1978. Family Therapy in Clinical Practice. New York: Rowan and Littlefield Publishers.

Bronfenbrenner, U. 1979. The Ecology of Human Development: Experiments by Nature and Design.

Cambridge: Harvard University Press.

Brown, J. 2008. “Is Bowen's Theory Still Relevant in Family Therapy Fields?” Journal of the Counsellors and Psychotherapists Association of New South Wales. 3: 1-17.

Carlini-Marlatt, B. 2005. Grandparents in Custodial. Curitiba: Catholic University of Parana. Christenson, S. L., and S. M. Sheridan. 2001. Schools and Families: Creating Essential Connections for Learning. New York: Guilford Press.

Cooter, K. S. 2006. "Issues in Urban Literacy: Counteracting Intergenerational Illiteracy." Reading Teacher 59 (7): 698-702. https://doi.org/10.1598/RT.59.7.9.

Creswell, J. W. 2007. Qualitative Inquiry and Research Design: Choosing Five Approaches. University of Nebraska-Lincoln: Sage.

Cuban, L. 2011. Larry Cuban on School Reform and Classroom Practice. Accessed 14 May 2013. https:// larrycuban.wordpress.com/.

Department of Basic Education. 2014. National Education Infrastructure Management System: National Assessment Report. Pretoria: Government Printers.

De Vos, A. S., H. Strydom, C. B. Fouché, and C. S. L. Delport. 2002. Research at Grassroots: For the Social Sciences and Human Service Professions. Pretoria: Van Schaik.

Drajea, A. J., and C. O'Sullivan. 2014. "Influence of Parental Education and Family Income on Children's Education in Rural Uganda." Global Education Review 1 (3): 149-66.

Farris, P. J., and M. R. Denner. 1991. "Guiding Illiterate Parents in Assisting their Children in Emergent Literacy." Reading Horizons 32 (1): 63-72. Accessed 4 June 2017. http://scholarworks.wmich.edu/reading_horizons/vol32/iss1/7.

Hamann, M., and M. Tuinder. 2012. Introducing the Eastern Cape: A Quick Guide to its History, Diversity and Future Challenges. Stockholm: Stockholm University.

Harmse, A., P. Blaauw, and R. Schenck. 2009. "Day Labourers, Unemployment and Socioeconomic Development." Urban Forum 20: 363-77. 
Hoover-Dempsey, V. K., A. C. Battiato, J. M. T. Walker, R. P. Reed, and J. M. DeJong. 2001. "Parental Involvement in Homework." Educational Psychologist 36 (3): 195-209. https://doi.org/10.1207/S15326985EP3603_5.

Khan, R. M. A., N. Iqbal, and S. Tasneem. 2015. "The Influence of Parents' Educational Level on Secondary School Students: Academic Achievements in District Rajanpur." Journal of Education and Practice 6 (16): 76-80.

Kinyua, J. N. 2013. "Challenges Faced by Grandparents in Managing Emotional and Behavioural Problems of Orphans in the Era of HIV/AIDS." International Journal of Arts and Entrepreneurship 1 (3): 329- 39.

Krueger, R. A., and M. A. Casey. 2014. Focus Groups: A Practical Guide for Applied Research. Thousand Oaks: Sage.

Lemmer, E. M., C. Meier, and J. N. van Wyk. 2006. Multicultural Education: An Educator's Manual. Pretoria: Van Schaik.

Loughran, S. B. 2008. "The Importance of Teacher/Parent Partnerships: Preparing Pre-Service and In-Service Teachers." Journal of College Teaching and Learning 5 (8): 35-38. https://doi.org/10.19030/tlc.v5i8.1239.

Lunga, N. R. 2009. "Challenges experienced by Grandparents in Raising their Grandchildren in Utrecht in KwaZulu-Natal.” PhD dissertation, University of Zululand.

Martínez, R., and A. Fernández. 2010. The Social and Economic Impact of Illiteracy: Analytical Model and Pilot Study. Santiago: UNESCO. Accessed 15 November 2017. http://unesdoc.unesco.org/images/o019/o01905/190571E.pdf.

Mathambo, V., and A. Gibbs. 2008. Qualitative Accounts of Family and Household Changes in Response to the Effects of HIV and AIDS: A Review with Pointers to Action. Cape Town: Human Science Research Council (HSRC) Press.

Menheere, A., and E. H. Hooge. 2010. "Parental Involvement in Children's Education: A Review Study about the Effect of Parental Involvement on Children's School Education with a Focus on the Position of Illiterate Parents." Journal of Teacher Education Network (6): 14457 .

Nelson Mandela Children's Fund (NMCF). 2001. Report: A Study into the Situation and Special Needs of Children in Child-headed Households. Johannesburg: NMCF.

Neuman, W. L. 2006. Social Research Methods: Qualitative and Quantitative Approaches. Boston: Pearson. 
Osborne, C., and S. McLanahan. 2007. "Partnership Instability and Child Well-being." Journal of Marriage and Family 69 (4): 1065-83. https://doi.org/10.1111/j.1741-3737.2007.00431.x.

Penn, H. 2005. Understanding Early Childhood Education: Issues and Controversies. Glasgow: Bell and Bain.

Perret, S., W. Anseew, and N. Mathebula. 2005. "Poverty and Livelihood in Rural South Africa. Investigating Diversity and Dynamics of Livelihood: Case Studies in Limpopo.” Project report number 05/01, University of Pretoria and Kellogg's Foundation.

Pomerantz, E. M., E. A. Moorman, and S. D. Litwack. 2007. "The How, Whom and Why of Parents' Involvement in Children's Academic Lives: More is Not Always Better." Review of Educational Research 77 (3): 373-410. https://doi.org/10.3102/003465430305567.

Quintal, G. 2016. "Matric Results 2015: Pass Rate Drops to 70,7\%.” Mail and Guardian, 5 January. Accessed 15 November 2017. https://mg.co.za/article/2016-01-05-matric-pass-ratedrops-to-707.

Roman, S. P. 2004. "Illiteracy and Older Persons: Individual and Societal Implications" Educational Gerontology 30 (2): 79-93. https://doi.org/10.1080/03601270490266257.

SEED (Scottish Executive Education Department). 2005. "Scottish Executive Education Department Communications Strategy: Final Report." Accessed 16 November 2017. http://www.gov.scot/Resource/Doc/920/o012096.pdf.

Sonke Gender Justice Network. 2013. "'Absent Fathers in South Africa.' Radio Guide: Episode 2. Men Care: HIV/AIDS, Gender, Equality, Human Rights.” Accessed 15 November 2017. http://www.men-care.org.

Statistics South Africa. 2014. General Household Survey 2013. Accessed 15 November 2017. https://www.statssa.gov.za/publications/Po318/P03182013.pdf.

UNESCO (United Nations Educational, Scientific and Cultural Organization). 2010. 2010 EFA. Globalalized. Oxford: Oxford University Press. Accessed 5 June 2017. http://unesdoc.unesco.org/images/o018/o01866/186606E.pdf

Visser, M. 2007. Contextualising Community Psychology in South Africa. Pretoria: Van Schaik.

Weigel, D. J., S. S. Martin, and K. K. Bennet. 2006. "Mothers' Literacy Beliefs: Connections with the Children's Literacy Development.” Journal of Early Childhood Literacy 6 (2): 191211. https://doi.org/10.1177/1468798406066444. 